\title{
Degradation of polyurethanes in vitro and in vivo: comparison of different models ${ }^{\alpha}$
}

\author{
Jack R. Frautschi ${ }^{\mathrm{a}, *}$, Joseph A. Chinn ${ }^{\mathrm{a}}$, Richard E. Phillips, Jr. ${ }^{\mathrm{a}}$, Q.H. Zhao ${ }^{\mathrm{b}}$, \\ James M. Anderson ${ }^{\mathrm{b}}$, Ravi Joshi ${ }^{\mathrm{c}}$, Robert J. Levy ${ }^{\mathrm{c}}$ \\ ${ }^{a}$ CarboMedics, 1300 B East Anderson Lane, Austin, TX 78752-1793, USA \\ ${ }^{\mathrm{b}}$ Departments of Macromolecular Science and Pathology, Case Western Reserve University, Cleveland, \\ OH 44106, USA \\ ${ }^{\mathrm{c}}$ Department of Pediatrics, University of Michigan Medical Center, Ann Arbor, MI 48109-0576, USA
}

(Received 8 February 1993; accepted 4 May 1993)

\begin{abstract}
This study compares and contrasts mechanisms of polyetherurethane (PEU) degradation in vitro and in vivo. Models comprising incubation with hydrogen peroxide in vitro $\left(\mathrm{H}_{2} \mathrm{O}_{2}\right)$, in vivo subcutaneous rat implant (SUBQ), and subcutaneous rat cage implant (CAGE) are described and compared with in vivo degradation of the pacemaker lead device retrieved after human implant (PACE). Experımental results support the hypothesis that stress accelerates PEU degradation. Scanning electron microscopy (SEM), gel permeation chromatography (GPC), and Fourier transform IR spectroscopy/attenuated total reflectance (FT-IR/ATR) evaluation of tested PEU samples suggests, for all models, decreased soft segment and increased ester functionality at the polymer surface These observations are consistent with a single, metal ion catalyzed, polyester intermediate, oxidative degradation mechanism common to all models, and with device performance in vivo. Model comparison suggests that in vitro $\mathrm{H}_{2} \mathrm{O}_{2}$ and in vivo SUBQ and CAGE models accurately mimic in vivo degradation of the pacemaker lead device (PACE).
\end{abstract}

Key words Degradation; Hyperoxide; In vitro; In vivo; Pacemaker lead; Polyurethane

\section{Introduction}

Polyetherurethanes (PEUs) are commonly used in biomedical applications due to their good mechanical properties [1] and relative biocompatibility [2]. Devices fabricated from PEU include artificial heart diaphragms, ventricular assist devices, pacemaker leads, and vascular grafts [3]. However, the in vivo stability of PEU has been questioned [4,5]. Premature failure of PEU cardiac pacing lead insulation has been reported [6-8]. Further, degradation of PEU was related to the quantity of soft segment in the polymer, i.e. stability

\footnotetext{
*Corresponding author.

${ }^{\alpha}$ Presented at the Surfaces in Biomaterials Symposium, Minneapolıs, USA, 14-16 October 1992
}

increased with decreased ether content [9]. Metal ion catalyzed degradation has been proposed $[10,11]$.

While PEU degradation in vitro upon incubation with enzyme [12-14] and metal ion solution [15] have been reported, more recent studies report oxidative degradation of PEU upon incubation with hydrogen peroxide $[16,17]$. The relevance of both oxidative and enzymatic PEU degradation in vivo remains uncertain. However, it is likely that dynamic interactions between cells and the polymer surface are relevant to PEU degradation. Initially, polymorphonuclear leukocytes (PMNs) are thought to undergo cellular activation, then become displaced by macrophages. These cells then coalesce to form foreign body giant cells (FBGCs) [18], which are purported to produce oxidizing 
agents such as hydrogen peroxide [19]. Preferential PEU degradation at the site of FBGC adherence has also been reported [20].

In this study, PEU degradation observed in the in vitro $\mathrm{H}_{2} \mathrm{O}_{2}$ model $[10]$ is compared with that observed in the in vivo SUBQ [21] and CAGE [22] models, and with that observed in PEU pacemaker leads retrieved after human implant. Based upon chemical evaluation of samples tested in each model, we propose that oxidative degradation occurs by a single, common, metal ion catalyzed mechanism through a polyester intermediate.

\section{Experimental}

In vitro incuhation of pacemaker leads with hydrogen peroxide $\left(\mathrm{H}_{2} \mathrm{O}_{2}\right)$

The in vitro degradation model has been described previously [10]. Briefly, pacing leads comprising a nickel-cobalt coil coated with brazed silver and insulated with Pellethane (PEU, Dow Chemical, Midland, $\mathrm{MI}$ ) were electronically paced in $3 \% \mathrm{H}_{2} \mathrm{O}_{2}$ for 180 days at $37 \mathrm{C}$. The solution was changed three times per week. Control samples were incubated with Ringer's lactate solution (2.58 $\mathrm{g} \mathrm{l}^{-1} \mathrm{NaCH}_{3} \mathrm{CH}(\mathrm{OH}) \mathrm{CO}_{2} \mathrm{H}, 6.00 \mathrm{~g} \mathrm{l}^{-1} \mathrm{NaCl}$, $0.30 \mathrm{~g} \mathrm{l}^{-1} \mathrm{KCl}, 0.20 \mathrm{~g} \mathrm{l}^{-1} \mathrm{CaCl}_{2} \cdot 2 \mathrm{H}_{2} \mathrm{O}, \mathrm{pH} 6.8$ ).

Samples were examined by scanning electron microscopy (SEM) (JSM-5400, Joel, Tokyo, Japan) for indications of gross degradation. SFM samples were sputter coated with gold-palladium to $100 \AA$ and examined at an accelerating voltage of $15 \mathrm{keV}$. Fourier transform IR spectroscopy/attenuated total reflectance (FT-IR/ATR)(FTS-40, BioRad, Boston, MA) was used to detect chemical changes that occurred during peroxide incubation. The ATR attachment utilized a KRS-5 crystal at an angle of $45^{\circ}$, which corresponds to a surface depth of approximately $1 \mu \mathrm{m}$. Molecular weight distributions of test and control samples were measured by gel permeation chromatography (GPC)(GPC II, Waters, Milford, MA) and compared. N,Ndimethylacetamide (DMAC) was used as the car- rier solvent and polystyrene as the molecular weight standard.

In vivo subcutaneous rat implant model of polymer degradation ( $S U B Q$ )

The SUBQ model, which has typically been used to evaluate calcification of pericardial tissue samples, has been described previously [21]. Briefly, dry Mitrathane (polyetherurethane urea (PEUU), Polymedica, Denver, CO) was dissolved at $10 \%(\mathrm{w} / \mathrm{v})$ in DMAC and poured onto a Teflon plate. After solvent was evaporated under vacuum, the polymer sheet was peeled from the plate. From the sheet were cut substrate samples $\left(1.0 \mathrm{~cm}^{2}\right.$, $0.023 \mathrm{~cm}$ thickness), which were then dipped in $10 \%(\mathrm{w} / \mathrm{v})$ Biomer (PEUU, Ethicon, Somerville, $\mathrm{NJ}$ ) in DMAC, and dried under vacuum. The dipping procedure was repeated until sample thickness was $0.038 \mathrm{~cm}$. Fifteen Biomer-coated Mitrathane samples were annealed at $125^{\circ} \mathrm{C}$ for $1 \mathrm{~h}$ to remove residual stress, then implanted subcutaneously in Sprague-Dawley rats as follows. (Biomer-coated Mitrathane samples rather than Biomer samples were used for reasons unrelated to PEU degradation.)

Rats weighing 50-60 g (Charles River Labs) were anesthetized with an intraperitoneal injection of $0.00857 \mathrm{mg} \mathrm{g}^{-1}$ xylazine and $0.057 \mathrm{mg} \mathrm{g}^{-1}$ ketamine. A small incision was made on the abdominal midline with scissors. The scissors were inserted into the incision and used to blunt dissect a subcutaneous pouch. A separate pouch was made for each implant. Four samples were implanted per animal, and samples were placed $2 \mathrm{~cm}$ apart. Each sample was inserted with forceps and the opening closed with a stainless steel wound clip. Each animal was again weighed following surgery and an identification tag placed on its ear.

Samples were retrieved after 60 days, rinsed in distilled, deionized water, and photographed. Samples were then examined under SEM, incubated with $0.6 \%$ buffered pepsin solution and examined by FT-IR/ATR, or incubated first with pepsin, then with solvent in an attempt to solubilize from 
the bulk sample the topmost surface layers, from which molecular weight distribution was measured by GPC.

In vivo subcutaneous rat cage implant model (CAGE)

The CAGE model has also been described previously [11]. Briefly, either dry Biomer, or a proprietary dry Biomer-like polymer, "B2", was dissolved at $10 \%(\mathrm{w} / \mathrm{v})$ in DMAC then cast against Teflon rods of $4 \mathrm{~mm}$. After solvent was evaporated under vacuum, each cast tube was extracted for $24 \mathrm{~h}$ with sterile, deionized water and dried to constant weight. Samples were cut to $2 \mathrm{~mm}$ specimens, each of which was strained to $400 \%$, secured around a polysulfone mandrel, then sutured with Green "Silky" II PolyDEK 108-Y 4-0 (Deknatel, Fall River, MA; catalog number X-5262). Test specimens were trimmed as necessary, sterilized with ethylene oxide, and placed into stainless steel mesh cages. Fifteen samples of each test material were then implanted subcutaneously in SpragueDawley rats (one sample per cage, one cage per animal).

Samples were retrieved after 5, 10, and 15 weeks and rinsed in distilled, deionized water. Samples were then either examined for rupture and cracking under SEM, or examined for chemical changes by FT-IR/ATR.

\section{Human pacemaker lead device implant ( $P A C E$ )}

Pacer leads comprising an MP-35N nickel-cobalt-chromium coil insulated with Pellethane were retrieved after 3 years human implant and returned for analysis. Proteinaceous deposits were removed by $24 \mathrm{~h}$ incubation with $0.6 \%$ buffered pepsin solution. Pellethane insulation was then analyzed for chemical changes by FT-IR/ATR.

\section{Results}

\section{$S E M$ examination of degraded $P E U$ samples}

SEM micrographs of PEU samples before and after testing reveal significant degradation in some but not all models. Comparison of the Biomer sample prior to implant (CONTROL; Fig. 1(a)) with the Biomer sample retrieved after 60 days subcutaneous, unstressed, uncaged, rat implant (SUBQ; Fig. 1(b)) reveals no visual degradation. However, surface cracks and rupture were observed on Biomer samples retrieved after 10 weeks subcutaneous, stressed, caged, rat implant (CAGE; Fig. 1(c)). SEM micrographs of Biomer samples retrieved after 5 and 15 weeks, and of B2 samples retrieved after 5,10 , and 15 weeks were similar (data not shown). Comparison of the inner lumen of the Pellethane pacer lead prior to pacing in hydrogen peroxide (CONTROL; Fig. 2(a)) with the inner lumen of the lead paced 180 days in hydrogen peroxide reveals large surface cracks in the polymer $\left(\mathrm{H}_{2} \mathrm{O}_{2}\right.$; Fig. 2(b)). Comparison of the external surface of the Pellethane lead prior to implant (CONTROL; Fig. 3(a)) with the exterior surface of the lead retrieved after 3 years human implant (PACE; Fig. 3(b)) reveals similar cracking.

Cracks in the Pellethane leads were observed only at sites of externally applied stress, both in vitro $\left(\mathrm{H}_{2} \mathrm{O}_{2}\right)$ and in vivo (PACE). Stress in $\mathrm{H}_{2} \mathrm{O}_{2}$ was applied where the lead emerged from the apparatus, while stress in PACE was applied by coiling a section of the lead that was implanted subcutaneously.

\section{FT-IR/ATR examination of degraded PEU samples}

FT-IR/ATR spectra of Biomer degraded in vivo appear in Figs. 4(a) and 4(b) (SUBQ and CAGE, respectively). Spectra of Pellethane degraded in vitro $\left(\mathrm{H}_{2} \mathrm{O}_{2}\right)$ and in vivo (PACE) appear in Figs. 5(a) and 5(b), respectively. Main peak assignments for both Pellethane and Biomer have been reported previously [23].

\section{Measurement of polymer molecular weight distribution by GPC}

GPC measurement of the molecular weight distribution of Pellethane $\left(\mathrm{H}_{2} \mathrm{O}_{2}\right)$ samples reveals significant reduction in number average molecular 


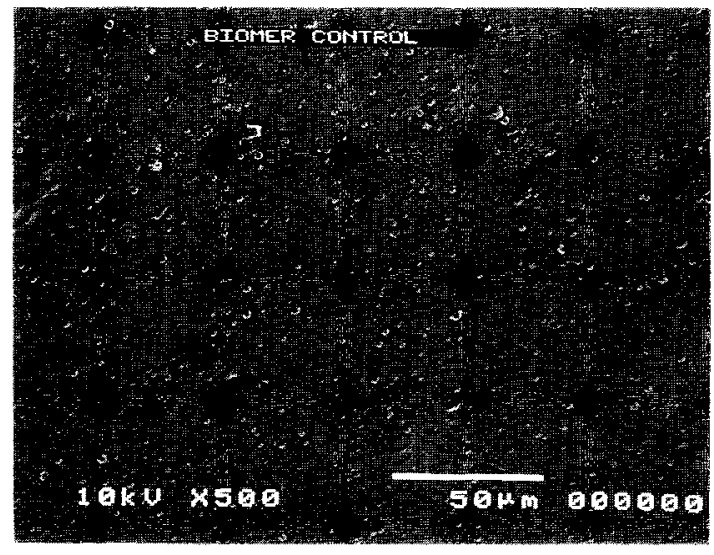

(a)

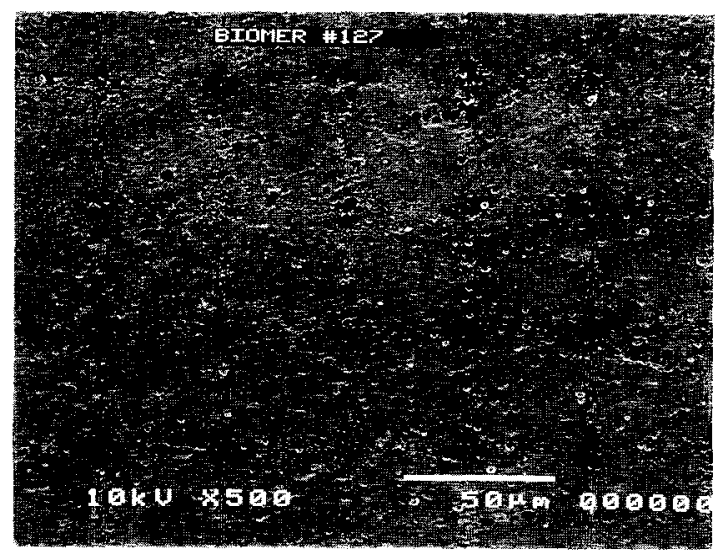

(b)

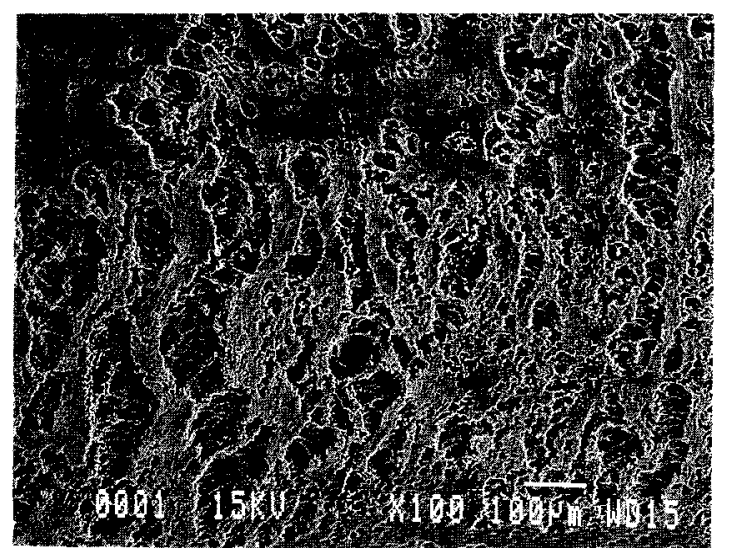

(c)

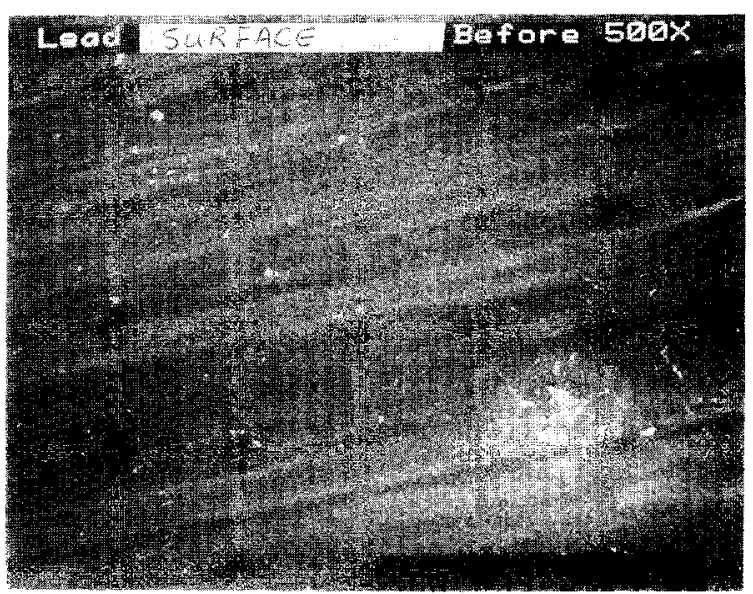

(a)

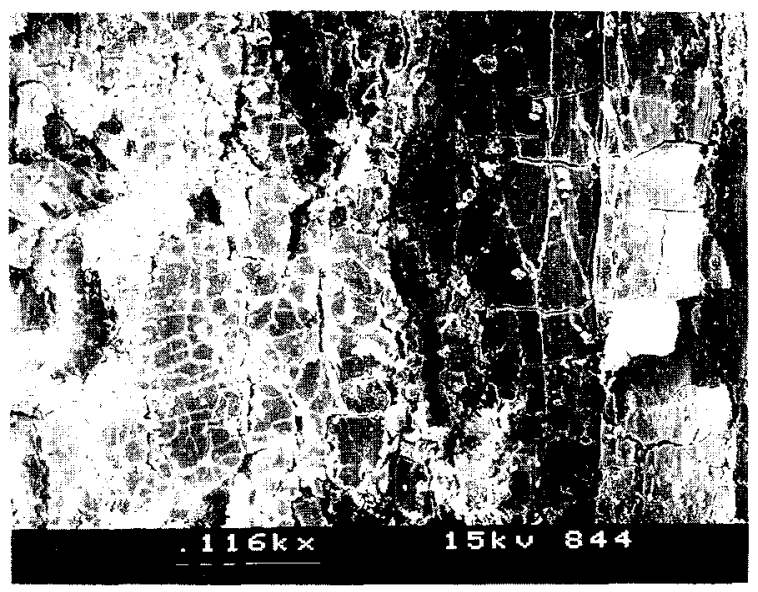

(b)

Fig. 2. (a) SEM micrograph of Pellethane pacer lead (inner lumenal surface) prior to incubation with hydrogen peroxide; magnification, $500 \times($ CONTROL). (b) SEM micrograph of Pellethane pacemaker lead (inter lumenal surface) paced 180 days in $3 \%$ hydrogen peroxide solution at $37 \mathrm{C}$; magnification, $500 \times\left(\mathrm{H}_{2} \mathrm{O}_{2}\right)$.

weight $\left(\mathrm{MW}_{\mathrm{n}}\right)$ (Table 1). However, the $\mathrm{MW}_{\mathrm{n}}$ of $\mathrm{B} 2$ (CAGE) samples was greater than, and that of Biomer (SUBQ) samples not significantly different from, the value for unimplanted controls. Neither

Fig. 1. (a) SEM micrograph of Biomer prior to implant; magnification, $500 \times$ (CONTROL). (b) SEM micrograph of Biomer sample implanted for 60 days subcutaneously in rats; magnification, $500 \times($ SUBQ). (c) SEM micrograph of Biomer sample (strained to $400 \%$ and caged) implanted for 10 weeks subcutaneously in rats; magnification, $500 \times(\mathrm{CAGE})$. 
Biomer (CAGE), nor Pellethane (PACE) samples were analyzed by GPC.

\section{Discussion}

One in vitro $\left(\mathrm{H}_{2} \mathrm{O}_{2}\right)$ and two in vivo (SUBQ and CAGE) models were used to study PEU degradation. However, experiments were conducted independently and therefore, implantation and incubation times, as well as the particular

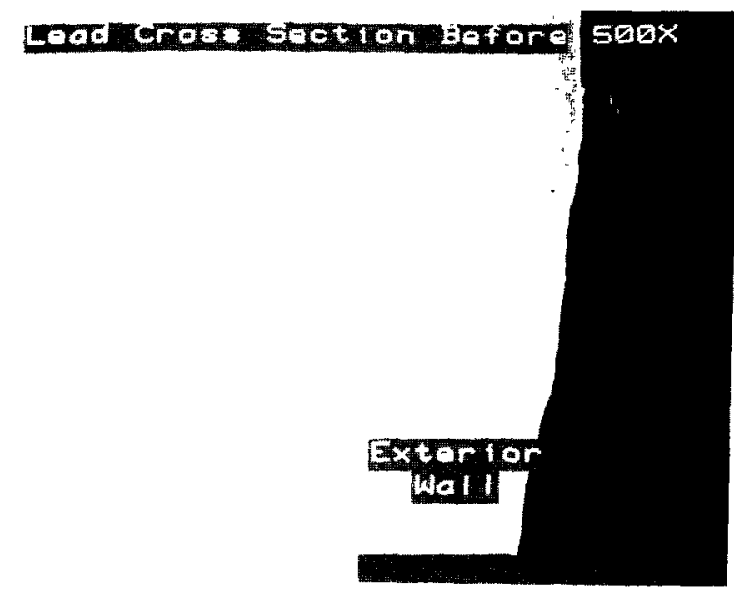

(a)

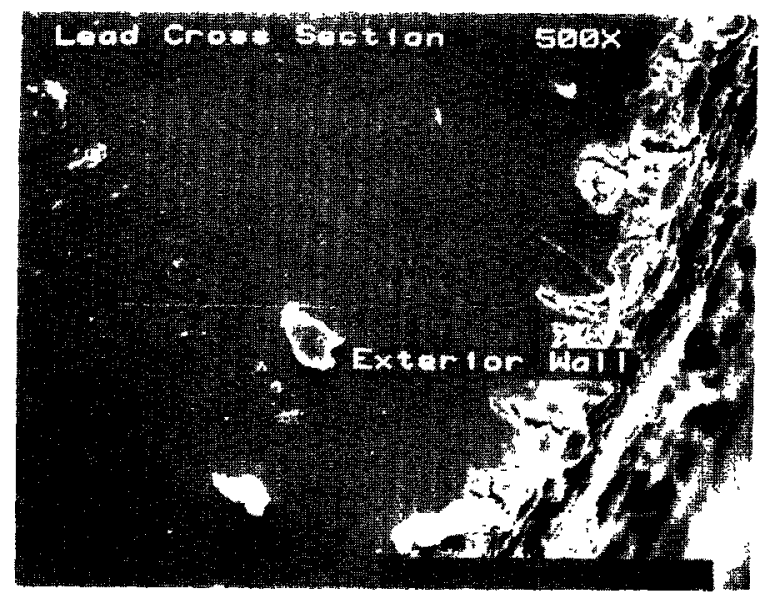

(b)

Fig. 3. (a) SEM micrograph of Pellethane pacemaker lead (exterior surface) pror to human implant, magnification, $500 \times$ (CONTROL). (b) SEM micrograph of Pellethane pacemaker lead (exterior surface) retrieved after 3 years human implant; magnification, $500 \times$ (PACE). samples tested, differ in each experiment. Nonetheless, results compared favorably with in vivo pacemaker lead device performance (PACE).

Experimental observations support the hypothesis that stress accelerates PEU degradation. Cracks in the Pellethane leads were observed only at sites of externally applied stress, both in vitro $\left(\mathrm{H}_{2} \mathrm{O}_{2}\right.$; Fig. 2(b) and in vivo (PACE; Fig. 3(b)). Cracking in vivo was observed in stressed Biomer (Fig. 1(c)) and B2 (data not shown) (CAGE), but not unstressed Biomer (Fig. 1(b)) or B2 (data not shown) (SUBQ) samples. (Unstressed Biomer was not tested, and degradation of unstressed B2 was not observed in the CAGE model, data not shown, )

Metal ion catalyzed oxidation is generally accepted as the mechanism for pacemaker lead device failure [10]. Surface cracks of Pellethane $\left(\mathrm{H}_{2} \mathrm{O}_{2}\right)$ samples were observed only at the stressed polymer-metal interface. However, degradation of the exterior surface of Pellethane (PACE) samples (Fig. 3(b)) was observed, due in part to the metal ion concentration in the subcutaneous environment.

\section{Changes in the molecular weight distribution of degraded PEU}

While the $\mathrm{MW}_{\mathrm{n}}$ value of Pellethane samples decreased upon peroxide incubation in the $\mathrm{H}_{2} \mathrm{O}_{2}$ model, that of Biomer did not significantly change in the SUBQ, and that of B2 increased in the CAGE models. Increased $\mathrm{MW}_{\mathbf{n}}$ of Biomer upon incubation with a silver nitrate solution [15], and after subcutaneous rat and canine implants [24] has been reported previously. Increased $\mathrm{MW}_{\mathrm{n}}$ was attributed to crosslinking of the polymer, and may also reflect the loss of low molecular weight fragments. While FT-IR spectra suggested degradation of high molecular weight chains in Biomer (SUBQ) samples, no change in $\mathrm{MW}_{n}$ value was observed. This suggests degradation, in the absence of stress, at the surface but not the bulk of the polymer. 


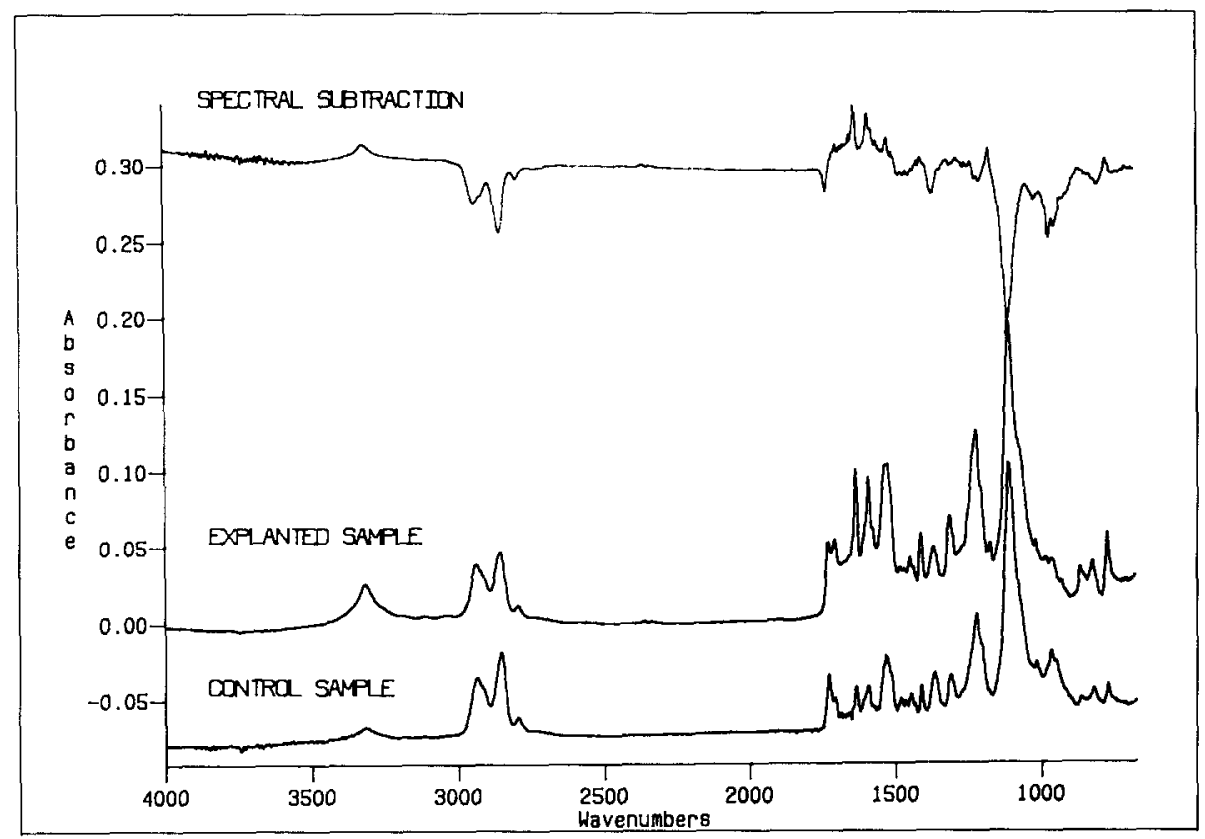

(a)

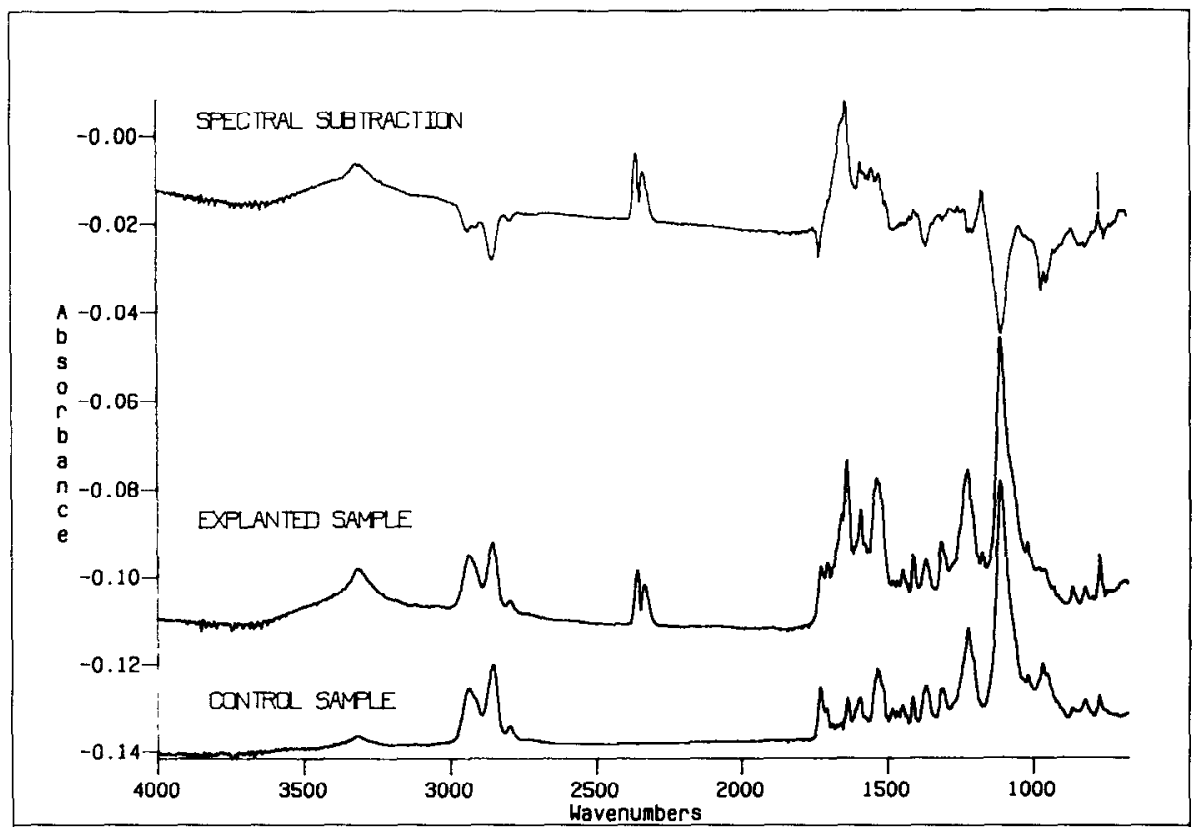

(b)

Fig. 4. (a) FT-IR spectrum of Biomer (SUBQ model); bottom, control, prior to implant; center, after 60 days subcutaneous rat implant: top, spectral subtraction (implant - control). (b) FT-IR spectrum of Biomer (CAGE model); bottom, control, prior to implant; center, after 10 weeks subcutancous rat cage implant; top, spectral subtraction (implant-control). 


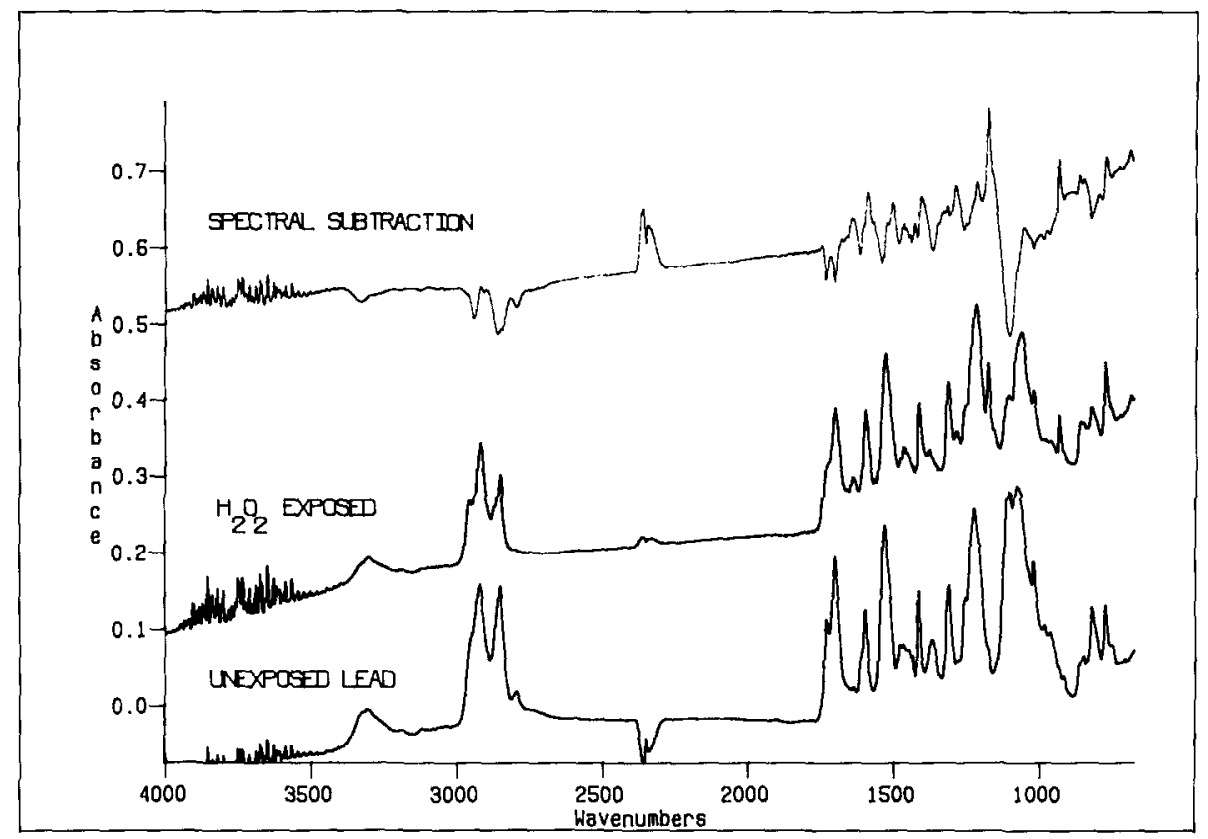

(a)

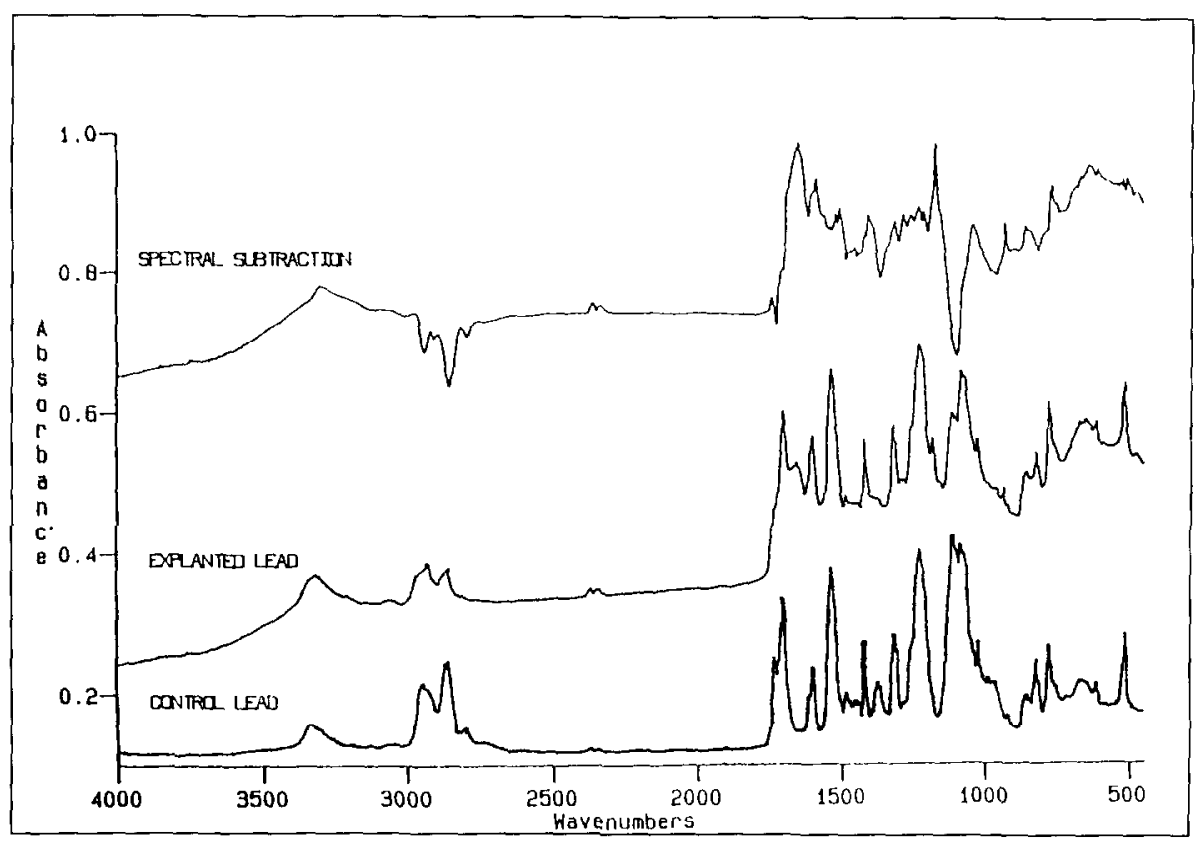

(b)

Fig. 5. (a) FT-IR spectrum of Pellethane pacer lead, inter lumenal surface $\left(\mathrm{H}_{2} \mathrm{O}_{2}\right.$ model); bottom, prior to incubation; center, paced 180 days in $3 \%$ hydrogen peroxide; top, spectral subtraction (implant - control). (b) FT-IR spectrum of Pellethane pacer lead, exterior surface (PACE model); bottom, control, prior to implant; center, after 3 years human subcutaneous implant; top, spectral subtraction (implant-control). 
Table 1

Number average molecular weight $\left(\mathrm{MW}_{\mathrm{n}}\right)(\mathrm{Da})$ of PEU and PEUU samples degraded in vitro and in vivo

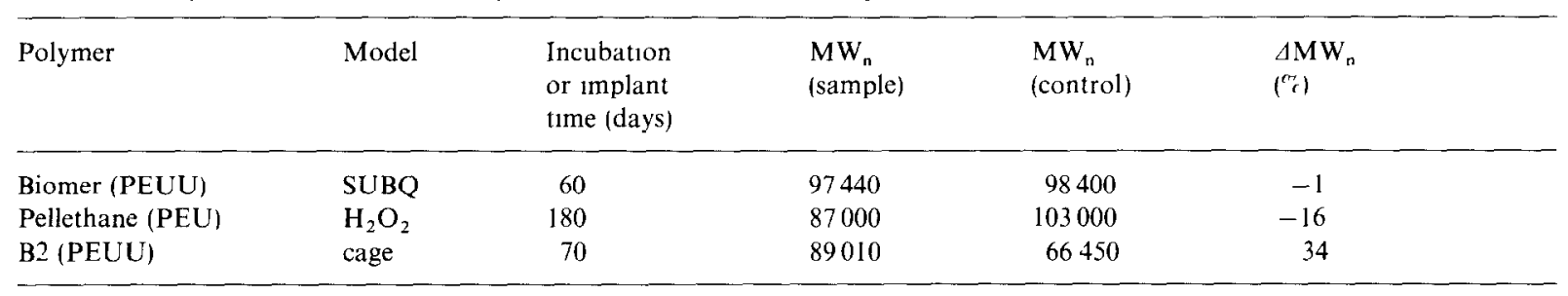

\section{Mechanism of PEU degradation}

Based upon the observation that PEU degradation in vivo occurs primarily at the ether linkage, and that antioxidants inhibit this degradation [25], a hyperoxide radical attack on the $\alpha$-carbon of the PEU soft segment was proposed as the first step in PEU degradation in the CAGE model [23]. Oxidation results in the formation of an ester linkage, which is susceptible to hydrolysis or esterase attack [26,27]. FT-IR/ATR analysis of PEUs tested using the $\mathrm{H}_{2} \mathrm{O}_{2}$, CAGE and SUBQ models, and of samples retrieved after human implant (PACE), support this mechanism.

Spectra of the PEUs degraded in vivo (SUBQ, CAGE, and PACE; Figs. 4(a), 4(b), and 5(b), respectively) share common features. All show decreased peak intensity at $1110 \mathrm{~cm}^{-1}$, characteristic of PEU soft segment, and corresponding increased peak intensities at 1525 and $1590 \mathrm{~cm}^{-1}$, characteristic of PEU hard segment. Increased peak intensities at 770 and $1174 \mathrm{~cm}^{-1}$, characteristic of polyester, were also observed. Decreased soft segment coupled with increased ester functionality at the surface suggests oxidative degradation.

Pellethane pacer leads degraded in vitro $\left(\mathrm{H}_{2} \mathrm{O}_{2}\right)$ display similar chemical changes. The spectrum of the inner lumen, which contacted the metal coil wire of the lead, also shows decreased peak intensity at $1110 \mathrm{~cm}^{-1}$ and increased intensities at 770 and $1174 \mathrm{~cm}^{1}$ (Fig. 5(a)). The spectrum of the outer polymer showed no such changes and resembled the control. These chemical changes are consistent with metal ion (from the wire coil) catalyzed oxidative degradation.
Pretreatment of stressed PEU with plasma, or with plasma component $\alpha_{2}$-macroglobulin $\left(\alpha_{2} M\right)$, prior to incubation with peroxide and cobalt chloride was reported to effect environmental stress cracking (ESC) [28]. ESC was hypothesized to result from synergistic interactions between $x_{2} M$, hyperoxide radicals, and applied material stress.

\section{Conclusions}

Applied external stress accelerates PEU degradation.

Degradation in the in vitro $\mathrm{H}_{2} \mathrm{O}_{2}$ model, the in vivo $\mathrm{SUBQ}$ and $\mathrm{CAGE}$ models, and the pacemaker lead device human implant (PACE) likely occurs by a common, metal ion catalyzed, oxidative degradation mechanism through a polyester intermediate.

\section{References}

1 J.W. Boretos and W.S. Pierce, Science, 158 (1976) 1481.

2 J.W. Boretos, D.E. Detmer and J.H. Donachy, J. Btomed Mater. Res., 5 (1971) 373.

3 H.E. Kambic, S.M. Murabayashi and Y. Nosé, Chem. Eng. News, April 14, (1986) 31

4 M. Szycher, J. Biomater. Appl, 3 (1988) 297.

5 K.B. Stokes, J. Biomater. Appl., 3 (1988) 228.

6 K.B. Stokes and K Cobran. Biomaterials. 3 (1982) 225.

7 C L. Byrd, W. McArthur, K Stokes, M. Sivia. W.Z. Yahr and J. Green, Pace, 6 (1983) 868.

8 L.M. van Gelder and M.I.H. El Gamal, Pace, 6 (1983) 834

9 M. Szycher, D. Dempsey and V.L. Poirier, Surface Fissuring of Polyurethane-based Pacemaker Leads, Second World Congress on Bomaterials, Tenth Annual Meeting of the Society for Biomaterials, Washington, DC, 1984, p. 24

10 K.B. Stokes, A. Court and P. Urbanski. J. Biomater. Appl., 1 (1987) 411.

11 R.E. Phillips, M.C. Smith and R.J Thoma, J. Biomater. Appl., 3 (1988) 207

12 S.K. Phua, E. Castillo, J.M Anderson and A. Hiltner, J. Biomed Mater. Res., 26 (1992) 1019. 
13 B.D. Ratner, K.W. Gladhill and T.A. Horbett, J. Biomed. Mater Res., 22 (1988) 509.

14 M. Bouvier, A S. Chawla and I. Hinberg, J Biomed. Mater. Res., 25 (1991) 773.

15 A. Takahara, A.J. Court, R.W. Hergenrother and S.L. Cooper, J. Biomed. Mater. Res., 25 (1991) 341.

16 G.F. Meijs, S.J. McCarthy, E. Rizzardo, Y.-C. Chen, R.C. Chatelier. A. Brandwood and K. Schındhelm, J. Biomed. Mater. Res., 27 (1993) 345.

17 B.J. Tyler and B.D. Ratner, J. Bromed. Mater. Res., 27 (1993) 327.

18 Q. Zhao, J. Anderson and A. Hiltner, J. Biomed. Mater. Res., 26 (1992) 1019.

19 T. Krause, F. Robertson and R. Greco, J. Biomed. Mater. Res.. 27 (1993) 65.

20 Q. Zhao, N. Topham, J.M. Anderson, A. Hiltner, G.A. Lodoen and CR, Payet, J. Bromed. Mater. Res., 25 (1991) 177 .
21 F.J. Schoen, J.W. Tsao and R.J. Levy, Am. J. Pathol., 123 (1986) 134.

22 R. Marchant, A. Hiltner. C. Hamlin, A. Rabinovitch, R. Slobodkın and J.M. Anderson, J. Biomed Mater. Res., 17 (1983) 301.

23 Y. Wu, C. Sellitti, J. Anderson, A. Hiltner, G.A. Lodoen and C. Payet, J. Appl. Polym. Sci., 46 (1992) 201.

24 R. Hergenrother, H. Wabers and S.L. Cooper, J. Appl. Biomater., 3 (1992) 17.

25 Y. Wu, Q. Zhao, J. Anderson, A. Hultner, G. Lodoen and C. Payet, J. Biomed. Mater. Res., 25 (1991) 725.

26 C.S. Schollenberger and F.D. Steward, J. Elastoplast., 3 (1971) 28

27 M.D. Lelah and S.L. Cooper, Polyurethanes in Medicine, CRC Press, Boca Raton, FL, 1986, pp 205-206.

28 Q.H Zhao, A.K. McNally, K.R. Rubin, M. Renıer, Y. Wu, V. Rose-Caprara, J.M. Anderson, A. Hiltner, P. Urbansk1 and K. Stokes, J. Biomed. Mater. Res., 27 (1993) 379. 